\title{
Projected Response of Typical Detonators to Electrostatic Discharge (ESD) Environments
}

M. J. Wilson

\section{December 20, 2002}
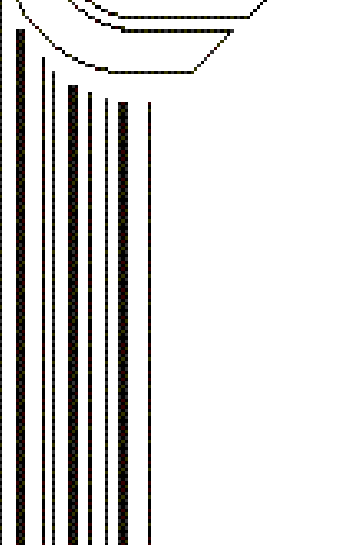


\section{DISCLAIMER}

This document was prepared as an account of work sponsored by an agency of the United States Government. Neither the United States Government nor the University of California nor any of their employees, makes any warranty, express or implied, or assumes any legal liability or responsibility for the accuracy, completeness, or usefulness of any information, apparatus, product, or process disclosed, or represents that its use would not infringe privately owned rights. Reference herein to any specific commercial product, process, or service by trade name, trademark, manufacturer, or otherwise, does not necessarily constitute or imply its endorsement, recommendation, or favoring by the United States Government or the University of California. The views and opinions of authors expressed herein do not necessarily state or reflect those of the United States Government or the University of California, and shall not be used for advertising or product endorsement purposes.

This work was performed under the auspices of the U.S. Department of Energy by the University of California, Lawrence Livermore National Laboratory under Contract No. W-7405-Eng-48.

This report has been reproduced directly from the best available copy.

Available electronically at http://www.doc.gov/bridge

Available for a processing fee to the U.S. Department of Energy and its contractors in paper from

U.S. Department of Energy Office of Scientific and Technical Information P.O. Box 62

Oak Ridge, TN 37831-0062

Telephone: (865) 576-8401

Facsimile: (865) 576-5728

E-mail: reports@adonis.osti.gov

Available for sale to the public from

U.S. Department of Commerce

National Technical Information Service 5285 Port Royal Road

Springfield, VA 22161

Telephone: (800) 553-6847

Facsimile: (703) 605-6900

E-mail: orders@ntis.fedworld.gov

Online ordering: http://www.ntis.gov/ordering.htm

OR

Lawrence Livermore National Laboratory Technical Information Department's Digital Library http://www.llnl.gov/tid/Library.html 
UCRL-ID-145642

\title{
Projected Response of Typical Detonators to Electrostatic Discharge (ESD) Environments
}

\author{
Michael J. Wilson \\ Lawrence Livermore National Laboratory \\ P.O. Box 808 M/S L-153 \\ Livermore, CA 94550-9900
}

\begin{abstract}
The purpose of this discussion is to indicate the threshold values for low-order detonator response by using first principles applied to pin-to-pin configurations and associated limits in pin-to-case scenarios. In addition an attempt to define the electrical environment by first principles is shown to be inadequate and indicates the need to define the electrical insult by reasonable standards. A comparison of two accepted electrical models and a combination of the extreme reported levels from both standards are used to establish an extreme set of parameters for a safety assessment. A simplification of the critical electrical insult parameters is then shown and demonstrated to provide the initial screening protocol with easily defined electrical dimensions of action integral. Action integral and the conductive material properties are the basic parameters needed to define the solid, liquid, and gas phases of the material used for detonator bridge wires. The resulting material phases are directly related to detonator response thresholds. The discussion concludes by showing the ability of ESD insults to arc from pin-to-case, the limited knowledge of the associated arc initiation process, and the modeling need for a reasonable arc resistance in pin-to-case scenarios.

Background

Recent safety studies have highlighted the need to quantify detonator response to
\end{abstract}

low-level unintentional electrical environments. These electrical environments include sources of electrostatic discharge (ESD) which are further divided into two general categories: human ESD (HESD) or personnel ESD (PESD) and furniture ESD (FESD) or tool ESD (TESD).

The following discussion analyzes a case study to establish reasonable upper bounds (RUBs) for these electrostatic environments and related critical parameters, such as the action integral, of a typical detonator. Action integral is basically the non-dissipative energy from an electrical source or the energy divided by the resistance $(E / R)$ having units of ampere-squared $\bullet$ seconds $\left(\mathrm{A}^{2} \mathrm{~s}\right)$. The detonator used in this case study consists of a gold fuse, or bridge wire (BW), and a pentaerythritoltetranitrate (PETN)type high explosive (HE). First-principle calculations of the detonator response to specific environments are used to derive the average fuse response level for the action integrals needed to achieve the thresholds for PETN melt, fuse melt, and fuse vaporization. A population of the response is then calculated by assuming a normal distribution with a typical standard deviation. Mapping the associated action integral of the environmental insults onto the developed response curves indicates the possible detonator response.

Evaluating the unintentional DC and $\mathrm{AC}$ electrical environments goes beyond the scope of this discussion and as such is covered in other documentation. 


\section{Introduction}

HE detonators are intuitively considered to be susceptible to unintentional voltage environments. The most severe response is detonation. Lower-level responses are also of interest and include melting, burning, or deflagration of the HE. The two possible attachments discussed are pin-to-pin and pin-to-case. The focus of this discussion is primarily the response of detonators from pin-to-pin insults and does not infer the same response in a pin-to-case attachment.

When HE is used in a detonator configuration that, as in this case study, has an exploding bridge wire (EBW) as the fuse, or initiator, other detonator responses that are less violent than detonation may occur. In addition, the detonator fuse current parameters must meet or exceed critical levels to ensure detonation. Values below the detonation threshold may produce a response of concern other than detonation. Such responses include significant fuse heating, HE melting, HE deflagration, fuse melting, and fuse vaporization.

A critical aspect of assessing the detonator response is defining the environment. The initial environment of interest involves ESDs. To establish the RUB for this type of environment, or threat, the naturally occurring limits and voltagedeveloping processes are examined. The resulting bounds are then used to justify the definition of an extreme environment. After establishing a threat, a set of parameters defining a reasonable detonator, or victim, is used to project the low-level response. This projection is based on a reasonable population distribution for each of the insults used to define a low-level response. The remaining environments are then similarly defined, and corresponding responses are projected. Insult mitigation is then proposed based on the established coupling to the victim.

\section{The Electrostatic Environment}

We have all experienced the effects of electrostatics. For example, walking across carpets, removing clothes from dryers, and rubbing dissimilar materials together can sometimes cause one's hair to prickle. This effect is the direct result of a charge being transferred between two dissimilar materials when separated after contact. This type of charge transfer is known as triboelectrification. The amount of charge transfer $(Q)$ from one material to the other during contact is directly related to the difference between the work functions of the two materials. ${ }^{1}$ A simple view of the relationship can be written (Eq. 1) and can also be expanded to a more fundamental relationship (Eq. 2). ${ }^{2}$

$$
\begin{aligned}
& Q_{1}=\mathrm{k}\left(\phi_{1}-\phi_{2}\right) \\
& Q_{2}=C \times V=C\left(\phi_{1}-\phi_{2}\right) e^{-1} \\
& \text { where: } \\
& Q_{1} \text { and } \mathrm{Q}_{2}=\text { charge or ampere-seconds }(\mathrm{A} \cdot \mathrm{s}), \\
& \mathrm{k}=\text { constant, } \\
& \phi_{1}=\text { work function of material } 1(\mathrm{eV}), \\
& \phi_{2}=\text { work function of material } 2(\mathrm{eV}), \\
& \mathrm{C}=\text { capacitance between surfaces, } \\
& V=\text { voltage, and } \\
& e=\text { electric charge }(1.60203 \mathrm{E}-19 \mathrm{C}) .
\end{aligned}
$$

Each material's work function, or the ease at which the material gives up an electron, determines the material's resulting polarity. The material with the greater work function will have a resulting negative polarity in relation to the second material, which acts as the electron source material. Table 1 lists some commonly used materials of interest and their corresponding work functions. ${ }^{1,3}$

The charge transfer occurs during contact at distances on the order of $0.4 \mathrm{~nm}$ and continues until the materials are separated by a distance of approximately $1 \mathrm{~nm} .{ }^{1,2}$ Charge transfer occurs between 
dissimilar materials, including metal-tometal, metal-to-dielectric, and dielectric-todielectric, during contact/separation events. The theoretical triboelectrification level (Eq. 2), which is based on the Fermi level, applies to a single contact/separation. As would be expected, multiple contacts and separations increase the total amount of charge transferred. A limit to the charging process has been demonstrated experimentally, thereby providing an empirically derived constant $\mathrm{k}=6 \mathrm{E}-8 .^{2}$ For example, if the material parameters associated with $U$ and PTFE, as given in Table 1, have a nominal charge transfer $Q$ of $18 \mathrm{E}-8 \mathrm{C}$, then the plastic will have a negative voltage in relation to the metal.

Table 1. Commonly used materials and their measured work functions.

\begin{tabular}{|c|c|}
\hline Material & $\begin{array}{c}\text { Work function } \\
\text { experimental value } \\
\phi(\mathrm{eV})\end{array}$ \\
\hline \multicolumn{2}{|l|}{ Metals } \\
\hline aluminum (Al) & 4.28 \\
\hline gold (Au) & 5.1 \\
\hline carbon $(\mathrm{C})$ & 5.0 \\
\hline copper $(\mathrm{Cu})$ & 4.65 \\
\hline nickel (Ni) & 5.15 \\
\hline uranium (U) & 3.63 \\
\hline \multicolumn{2}{|l|}{ Plastics } \\
\hline $\begin{array}{l}\text { polytetrafluoroethylene } \\
\text { (PTFE) }\end{array}$ & 6.71 \\
\hline $\begin{array}{l}\text { polycarbonate } \\
\text { (Lexcan) }\end{array}$ & 3.85 \\
\hline pyrex & 4.84 \\
\hline quartz & 4.87 \\
\hline nylon & 4.71 \\
\hline acrylic & 4.3 \\
\hline
\end{tabular}

The prickling effect that we sometimes experience is a result of the electrostatic voltage that has built up in a representative capacitance by triboelectrification (Eq. 3).

$$
V=Q \times C^{-1}
$$

As the cumulative charge of the capacitor increases, the ESD voltage reaches a corona, or partial discharge inception level, which is a limiting factor of triboelectrification.

Corona activity occurs when the field stress $(E)$ exceeds the strength of the surrounding dielectric media. For the case study discussed in this paper, the environment is assumed to be air. The strength of air is given by Paschen's law for uniform fields and can be solved when $d=1 \mathrm{~cm}$ for a maximum field stress $\left(E_{\max }\right)$ of $30 \mathrm{kV} / \mathrm{cm}$ by using Eq. $4{ }^{4}$ (Note that the cited equation does not include the limiting factor of humidity. Slight increases in triboelectrification are observed at low humidity. ${ }^{2}$ )

$$
\begin{aligned}
E_{\max } & =V / d \\
& =24.2\left(\frac{293 p}{760 T d}\right)+6.08\left(\frac{293 p}{760 T d}\right)^{0.5}
\end{aligned}
$$

where:

$E_{\max }=$ maximum field stress $(\mathrm{kV} / \mathrm{cm})$,

$V=$ voltage $(\mathrm{kV})$,

$p=$ pressure (Torr),

$T=$ temperature $(\mathrm{K})$, and

$d=$ separation distance between electrodes $(\mathrm{cm})$.

Before corona activity occurs, another less obvious limiting factor takes place between the two separating materials. In the case of metal/metal separation, the electrons that have migrated toward the higher work function material rapidly return by a backflowing or tunneling process to the surface of the source material. These back-flowing currents are limited by the surface resistance of the separating materials, which is smaller for metals than for dielectrics. Because of this rapid tunnel process, only a slight charge remains on the higher work function material.

In the case of triboelectrification involving metal/dielectric or 
UCRL-ID-145642

dielectric/dielectric, a significant increase in the surface resistance of dielectrics accounts for the increase in the residual charge after separation. When the tunneling process stops (when the separation distance equals approximately $1 \mathrm{~nm}$ ), air breakdown continues to discharge the separating materials. The air arcing limiting factor continues until the $E_{\max }$ falls below the intrinsic strength of the surrounding dielectric media, in this case, air. The speed of the separation can then be seen as one factor contributing to the residual charge between the two dissimilar materials. A fast separation provides for a higher residual charge transfer than in a gradual separation. During a gradual separation, the tunneling process is extended, thereby increasing the back-flow time and allowing the corona activity to initiate at distances away from the still contacted point. This prolongs the time spent in the corona discharge phase.

Even though a fundamental understanding of the triboelectrification process can be used to bound the charge transfer during contact/separation, the electrical environment of concern has not been adequately defined. However, understanding the charging of a subject, or source, and the discharging process to a target, or victim, can assist researchers in maximizing efforts to mitigate possible adverse environments and responses. An alternate and preferred method of defining the threat is by using an electrical-equivalent circuit. Using the models accepted by the ESD community, it is possible to establish a RUB based on the appropriate extreme parameter. The parameters of capacitance and voltage associated with this view show that a conductive charge distribution accounts for the significant charge stored in the severe or extreme PESD environment. 
UCRL-ID-145642

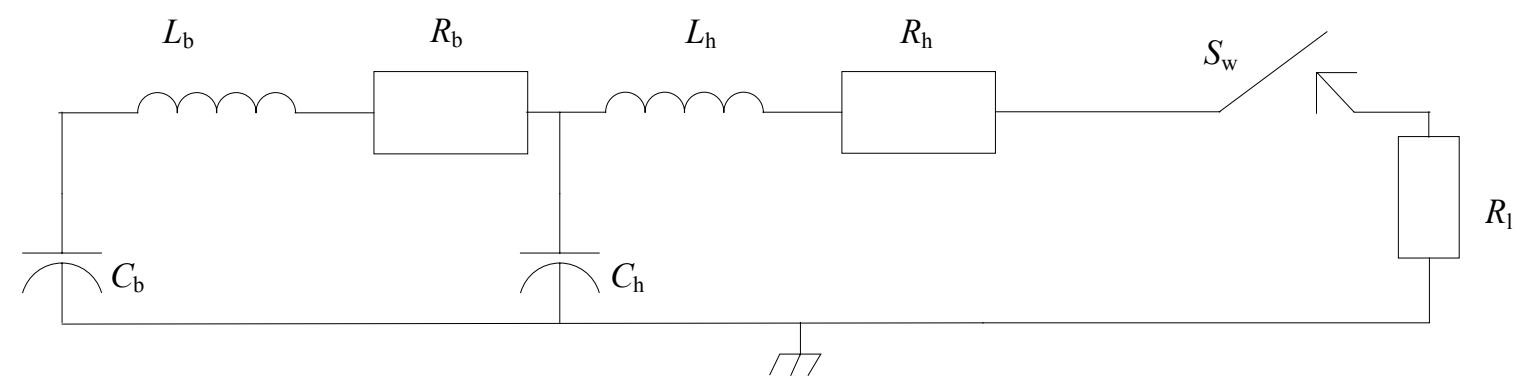

Figure 1. The electrical circuit used to describe the Fisher ESD environment provides a justifiable human model (HESD).

\section{The Personnel Electrostatic Environment}

The initial ESD environment of concern in this case study is human or personnel (HESD or PESD). This environment is a common unintentional environment of concern in the HE community and has widely accepted controls in place to mitigate adverse response. Most of the work involving HE detonators has shown that EBW and slapper detonators are insensitive to severe PESD types of insults relating to detonation. However, lower levels of detonator response have not been heavily investigated. For analysis purposes, two similar electrical-equivalent models are available to estimate the ESD environment. To reflect the conservative philosophy applied to risk assessment, this case study will compare the severity of each model as it relates to the extreme parameters associated with the appropriate environment.

The model used for most DOE assessments is the Fisher model and is shown in Figure 1. ${ }^{5}$ An alternate model, the IEEE STD 62.471998 , is more commonly used for assessment in the ESD community and is shown in Figure 2. ${ }^{6}$ The two circuit representations have obvious similarities but differ in a critical parameter of interest, the action integral, as shown in Table 2. Both circuit representations have dual tank

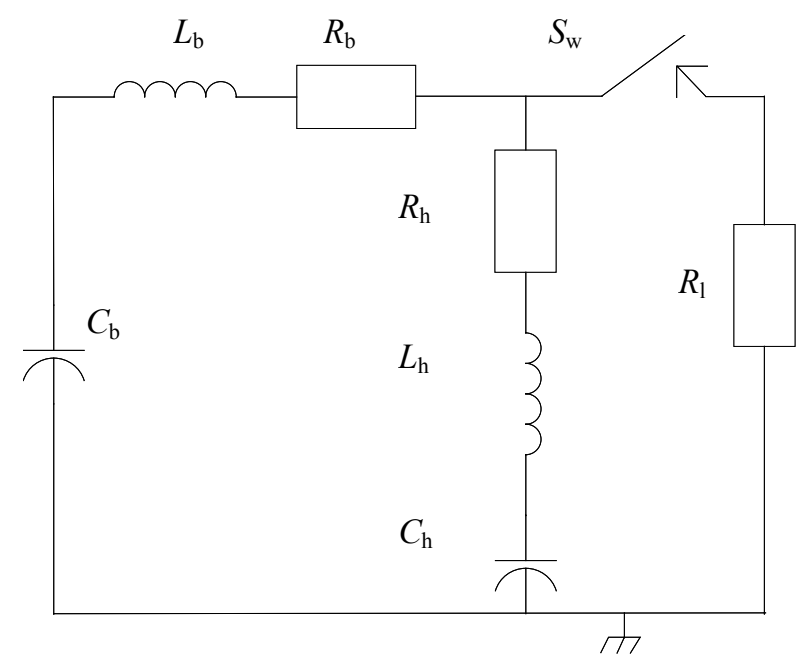

Figure 2. The IEEE PESD and FESD model, as shown above, provides a higher threat level than the Fisher HESD model.

circuits. The initial tank circuit represents the body as designated by capacitance, inductance, and resistance values respectively of $\mathrm{C}_{\mathrm{b}}, \mathrm{L}_{\mathrm{b}}$, and $\mathrm{R}_{\mathrm{b}}$ as shown in Figure 2. The second tank circuit similarly represents the hand shown in Figure 2 as $C_{h}$, $L_{h}$, and $R_{h}$. The values associated with each discrete component have the same ranges, as shown in Table 2. The reason for the action integral difference can be traced to the greater series resistance in the Fisher model when compared to the IEEE model. A further reduction in the insult will result when the victim impedance $\left(R_{\mathrm{l}}\right)$ is increased. 
Table 2. The range of values for each element that defines the HESD and PESD (the values used in this case study are shown in parentheses).

\begin{tabular}{|l|l|l|}
\hline $\begin{array}{l}\text { Component or } \\
\text { parameter }\end{array}$ & Fisher (HESD) & \multicolumn{1}{|c|}{$\begin{array}{c}\text { IEEE 62.47 } \\
\text { (PESD) }\end{array}$} \\
\hline $\begin{array}{l}\text { Body } \\
\text { capacitance }\left(C_{\mathrm{b}}\right)\end{array}$ & $\begin{array}{l}60 \text { to } 300 \mathrm{pF} \\
(300 \mathrm{pF})\end{array}$ & $\begin{array}{l}60 \text { to } 300 \mathrm{pF} \\
(300 \mathrm{pF})\end{array}$ \\
\hline $\begin{array}{l}\text { Body inductance } \\
\left(L_{\mathrm{b}}\right)\end{array}$ & $\begin{array}{l}0.5 \text { to } 2 \mu \mathrm{H} \\
(0.5 \mu \mathrm{H})\end{array}$ & $\begin{array}{l}0.5 \text { to } 2 \mu \mathrm{H} \\
(0.5 \mu \mathrm{H})\end{array}$ \\
\hline $\begin{array}{l}\text { Body resistance } \\
\left(R_{\mathrm{b}}\right)\end{array}$ & $\begin{array}{l}150 \text { to } 1500 \Omega \\
(250 \Omega)\end{array}$ & $\begin{array}{l}150 \text { to } 1500 \Omega \\
(150 \Omega)\end{array}$ \\
\hline $\begin{array}{l}\text { Hand } \\
\text { capacitance }\left(C_{\mathrm{h}}\right)\end{array}$ & $\begin{array}{l}3 \text { to } 10 \mathrm{pF} \\
(10 \mathrm{pF})\end{array}$ & $\begin{array}{l}3 \text { to } 10 \mathrm{pF} \\
(10 \mathrm{pF})\end{array}$ \\
\hline $\begin{array}{l}\text { Hand inductance } \\
\left(L_{\mathrm{h}}\right)\end{array}$ & $\begin{array}{l}0.05 \mathrm{to} 0.2 \mu \mathrm{H} \\
(0.1 \mu \mathrm{H})\end{array}$ & $\begin{array}{l}0.05 \text { to } 0.2 \mu \mathrm{H} \\
(0.05 \mu \mathrm{H})\end{array}$ \\
\hline $\begin{array}{l}\text { Hand resistance } \\
\left(R_{\mathrm{h}}\right)\end{array}$ & $\begin{array}{l}20 \text { to } 200 \Omega \\
(110 \Omega)\end{array}$ & $\begin{array}{l}20 \text { to } 200 \Omega \\
(20 \Omega)\end{array}$ \\
\hline \begin{tabular}{l} 
Switch $\left(S_{\mathrm{w}}\right)$ \\
\hline Load $\left(R_{\mathrm{l}}\right)$
\end{tabular} & \multicolumn{2}{|c|}{ Given as a short } \\
\hline $\begin{array}{l}\text { Severe action } \\
\text { integral } \\
(25 \mathrm{kV})\end{array}$ & $\begin{array}{l}2.6 \mathrm{E}-04 \mathrm{~A}^{2} \cdot \mathrm{s} \\
(94 \mathrm{~mJ})\end{array}$ & $\begin{array}{l}6.2 \mathrm{E}-04 \mathrm{~A}^{2} \cdot \mathrm{s} \\
(94 \mathrm{~mJ})\end{array}$ \\
\hline $\begin{array}{l}\text { Extreme action } \\
\text { integral } \\
(40 \mathrm{kV})\end{array}$ & $\begin{array}{l}6.6 \mathrm{E}-04 \mathrm{~A}^{2} \cdot \mathrm{s} \\
(240 \mathrm{~mJ})\end{array}$ & $\begin{array}{l}1.6 \mathrm{E}-03 \mathrm{~A}^{2} \cdot \mathrm{s} \\
(240 \mathrm{~mJ})\end{array}$ \\
\hline
\end{tabular}

A common parameter for both models is a voltage level of $25 \mathrm{kV}$ for a severe environment. In keeping with the DOE philosophy of using extreme levels when reasonably possible, this case study uses a voltage threat level of $40 \mathrm{kV}$ as the RUB, based on the reported measured level in reference 7. For the purpose of this discussion severe ESD and extreme ESD sources will refer to 25 and $40 \mathrm{kV}$ source potentials respectively. The circuit, however, will be in the IEEE configuration with the highest energy storage components and the lowest source impedance values, thereby providing an extreme ESD environment for use as a screening tool.

Slight variances in the relative location of the distributed inductance and resistance elements are used in this case study. The solution of the action integral remains the same, and the relationship of the inductance to capacitance is more readily seen when defining the source complex impedance $\left[(L / C)^{0.5}\right]$. Both models can also be used to describe the FESD with appropriate values. The dominant electrical parameter that determines the severity of the insult is the combined resistance of the source and victim.

A comparison of the two models used to define the PESD environment at the extreme voltage level of $40 \mathrm{kV}$ clearly indicates that the IEEE model provides the harsher insult. Figures 3, 4, and 5 show the calculated results for the current and action integral for the Fisher and IEEE models (shown in Figures 1 and 2, respectively) discharged into a $10-\mathrm{m} \Omega$ resistive load $\left(R_{1}\right)$. A representative EBW at $25^{\circ} \mathrm{C}$ will start with $R_{1}=13 \mathrm{~m} \Omega$ and will increase in resistance to levels of 2 to $5 \Omega$ at burst time. For the initial assessment a $10-\mathrm{m} \Omega$ resistance is used with the understanding that as the resistance value increases during current conduction a decrease in the action integral is anticipated from low resistance sources. As anticipated, the current and action integral are higher for the IEEE model than for the Fisher model. The values used for the circuit simulation are given in parentheses for each related component in Table 2. Table 2 also summarizes the associated action integral for each model and shows that the insult from the extreme IEEE PESD environment is higher than the insult from the extreme Fisher HESD model by a factor of 2.4 . 
UCRL-ID-145642

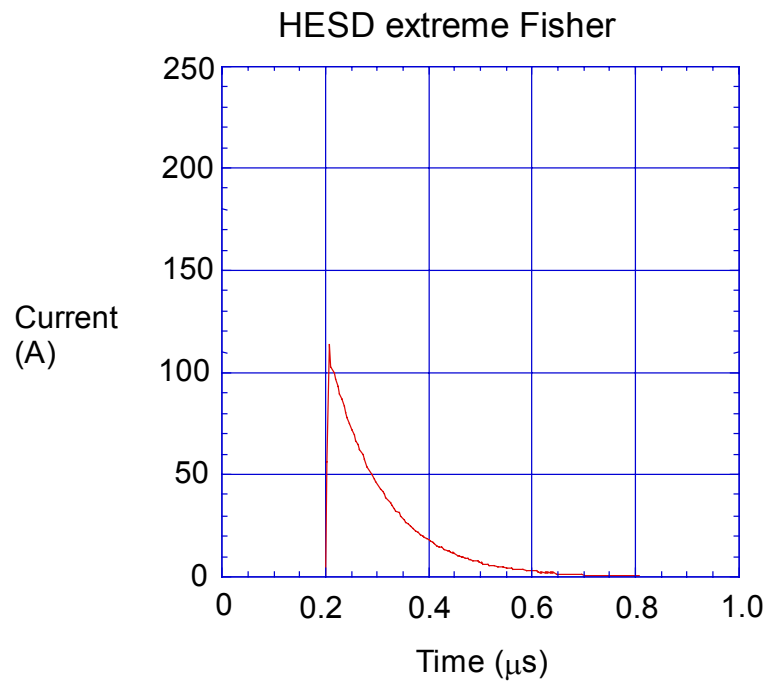

Figure 3. The computational current profile of an Fisher HESD insult imposed on a $10-\mathrm{m} \Omega$ EBW indicates a damped insult.

IEEE 62.47 indicates ranges for the values associated with PESD and FESD. The selected values may not occur coincidentally but are considered by the standard to be representative of a reasonable ESD environment.

The trend in the DOE community has been to use an extreme electrical environment when defining a RUB. Experimental efforts ${ }^{12,13}$ have shown that HESD-type environments are not a concern for our most sensitive detonator of interest. As a result, in work with detonator systems, ESD-type environments less severe than HESD have been screened as below the level of concern. The discussion continues with how the experimental evidence and the IEEE PESD environmental insult map onto the EBW population.

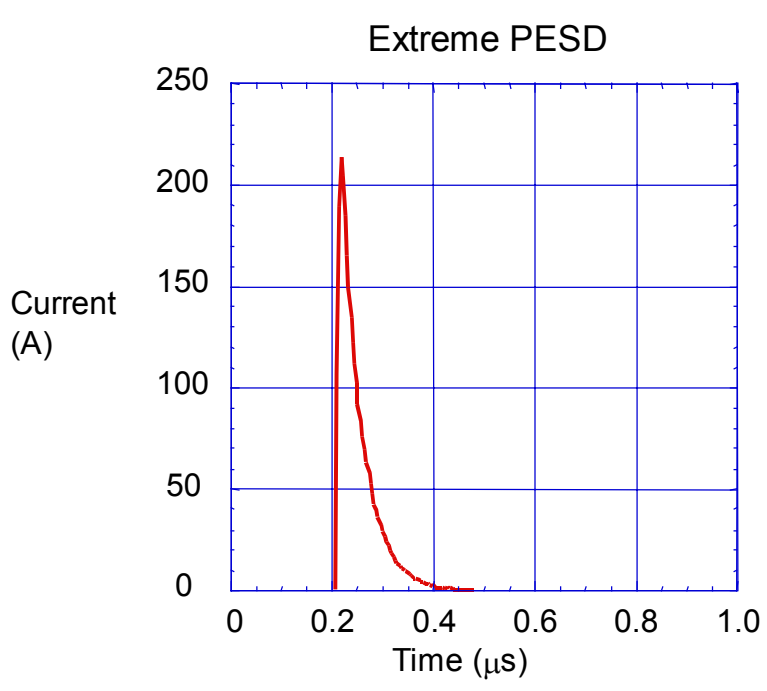

Figure 4. The computational current profile of an IEEE HESD insult imposed on a $10-\mathrm{m} \Omega$ EBW indicates a damped insult.

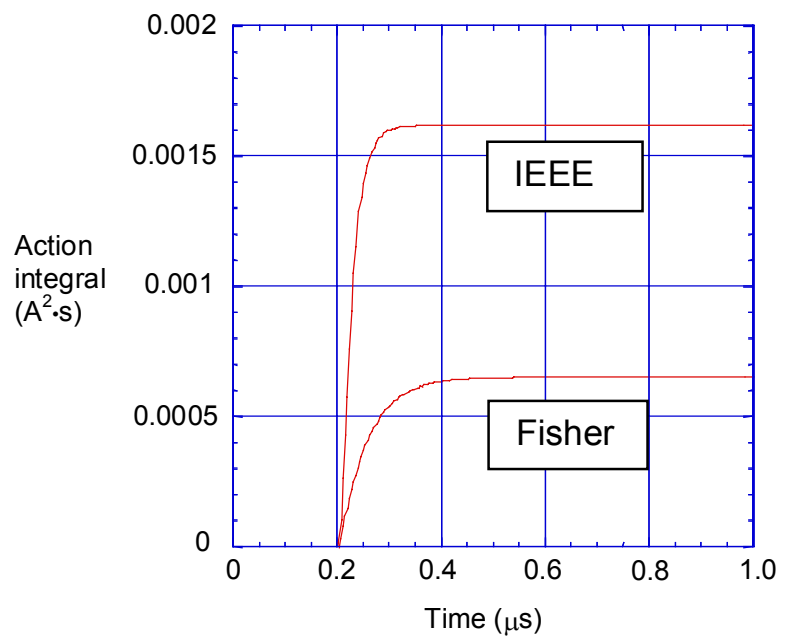

Figure 5. The corresponding action integrals of the IEEE and Fisher ESD show the anticipated difference between the two models, with the IEEE insult being higher than the Fisher insult by a factor of 2.4 . 


\section{The Detonator as a Victim of Interest}

For the purposes of this discussion, a typical EBW detonator, conceptually shown in Figure 6, was selected as a candidate for projecting the low-level response to these environments. The intrinsic material characteristics needed for calculating the responses are the temperatures at which the explosive melts, the explosive burns, the BW melts, and the BW boils or vaporizes. Even though the exact material parameters of various types of detonators are obviously different, low-level response projections appear possible using slightly modified parameters to reflect the appropriate unit.

The detonator used for this discussion consists of a PETN explosive device having an initial pressing density of $50 \%$, a gold 0.020-in. long, 0.0015-in. diameter BW, and encapsulated or pressed in a cylindrical aluminum case. The BW is centrally mounted on a 0.5 -in. diameter dielectric substrate. The component or victim is commercially available from RISI a subsidiary of Reynolds Industries Incorporated as an RP-1 EBW detonator.

PETN has an intrinsic density of 1.76 $\mathrm{g} / \mathrm{cm}^{3}$; a melting point of $141.3^{\circ} \mathrm{C}$; and a burn, or temperature at which the material becomes exothermic, of $180^{\circ} \mathrm{C} .{ }^{8,9}$ In addition, a reasonable manufacturing process for this type of detonator exhibits a population range of standard deviations between 10 and 12\% from the average detonator response.

\section{Additional Requirements of Detonation}

The critical part of the response assessment includes three independent occurring detonator parameters that are required for detonation. Table 3 provides the accepted threshold levels for typical PETN detonators. Since this discussion is tailored to a low-level response, the exact level or threshold for detonation is not an issue, other than being generally accepted to be

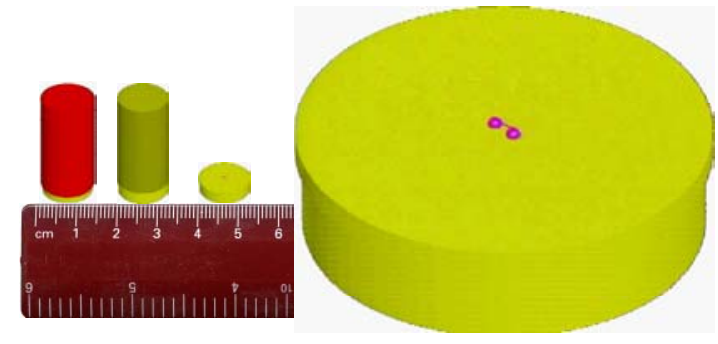

Figure 6. The victim of interest is a 1-in. long cylindrical, 0.5-in. diameter, PETN, EBW-type detonator. The header and EBW are shown in an expanded view to the right.

higher than the vaporization level indicated in Figures 10 and 11. The level of action integral needed for detonation is also specific to the detonator type. However, the additional critical parameters empirically found to be part of the integral detonation threshold of a typical PETN detonator are met when the current at burst time $\left(I_{\mathrm{B}}\right)$ is greater than $200 \mathrm{~A}$ and when all conditions occur within $5 \mu \mathrm{s}$. The three parameters required for detonation are used to set the initial ceiling for low-level response projections. (Higher levels indicate possible detonation.) Levels that are close are given additional considerations and a tighter review.

Table 3. The detonation threshold parameters for typical PETN-type detonators are used as indicators to establish the ceiling for low-level response projections.

\begin{tabular}{|l|l|}
\hline \multicolumn{1}{|c|}{ Threshold parameter } & \multicolumn{1}{c|}{ Value } \\
\hline Action integral $\left(\mathrm{A}^{2} \cdot \mathrm{s}\right)$ & Detonator-specific \\
\hline Current at burst time $\left(I_{\mathrm{B}}\right)$ & $\geq 200 \mathrm{~A}$ \\
\hline Time to burst $\left(I_{\mathrm{t}}\right)$ & $\leq 5 \mu \mathrm{s}$ \\
\hline
\end{tabular}


UCRL-ID-145642

\section{Pin-to-Pin Response}

The next step in projecting a low-level response of a detonator is to use the parameters of its basic material constituents to calculate the theoretical thresholds of interest. In this case study, the common parameter is the action integral given in units of $\mathrm{A}^{2} \cdot \mathrm{s}$. The previously described BW is used to project the victim response. The threshold calculations are then by the following relationship ${ }^{15}$ made to indicate the point at which the $\mathrm{EBW}$ reaches $140^{\circ} \mathrm{C}$, melts at $1064^{\circ} \mathrm{C}$, and vaporizes at $3080^{\circ} \mathrm{C}$.

$$
\Delta T=\frac{0.2389 \rho_{20}(1+\lambda \Delta T)}{c D A^{2}} \int I^{2} d t
$$

where:

$\Delta T=$ increase in temperature $\left({ }^{\circ} \mathrm{C}\right)$ from $20^{\circ} \mathrm{C}$

$I=$ Amperes

$t=$ seconds

$c=$ specific heat $\left(\mathrm{cal} / \mathrm{g} /{ }^{\circ} \mathrm{C}\right)$

$D=$ specific gravity [density] $\left(\mathrm{g} / \mathrm{cm}^{3}\right)$

$\rho_{20}=$ resistivity $(\Omega \bullet \mathrm{cm})$

$A=$ cross-sectional area $\left(\mathrm{cm}^{2}\right)$

$\lambda=$ temperature coefficient of resistance $\left(1 /{ }^{\circ} \mathrm{C}\right)$

The EBW responses listed in Table 4 are assumed to be the single-point calculations encompassing approximately $50 \%$ of the population. Allowing the typical standard deviation of $10 \%$ for manufactured products, a normal density distribution can be derived to indicate the population for the material response of interest. A reasonable approximation of a normal distribution is given in Eq. 5. ${ }^{10,11}$

$$
F(x)=(\sigma \sqrt{2 \pi})^{-1} \exp \left(-\frac{(x-\mu)^{2}}{2 \sigma^{2}}\right)
$$

$F(x)$ is the probability density function that provides the relative height of a normal distribution in units of sigma $(\sigma)$, or standard deviation, from the average $(\mu)$ of the population. The integral $\int F(d x)$, or area under the curve, is then representative of the
Table 4. The calculated action integral values to achieve the associated responses at an ambient temperature of $20^{\circ} \mathrm{C}$.

\begin{tabular}{|c|l|}
\hline $\begin{array}{c}\text { Action integral } \\
\left(\mathbf{A}^{\mathbf{2} \cdot \mathbf{s})}\right.\end{array}$ & \multicolumn{1}{|c|}{$\begin{array}{c}\text { EBW threshold } \\
\left({ }^{\circ} \mathbf{C}\right)\end{array}$} \\
\hline 0.013 & 140 \\
\hline 0.058 & 1064 (melts) \\
\hline 0.093 & 3080 (vaporizes) \\
\hline
\end{tabular}

entire population and as such has an area of 1. The vertical axis, $F(x)$, in Figures 7 and 8 is scaled to a normal distribution function (Eq. 5) with $\mu=0$ and sigma $(\sigma)=1$. The scaling results in the same peak value for all distributions, hence emphasizing their spreads for illustrative purposes.

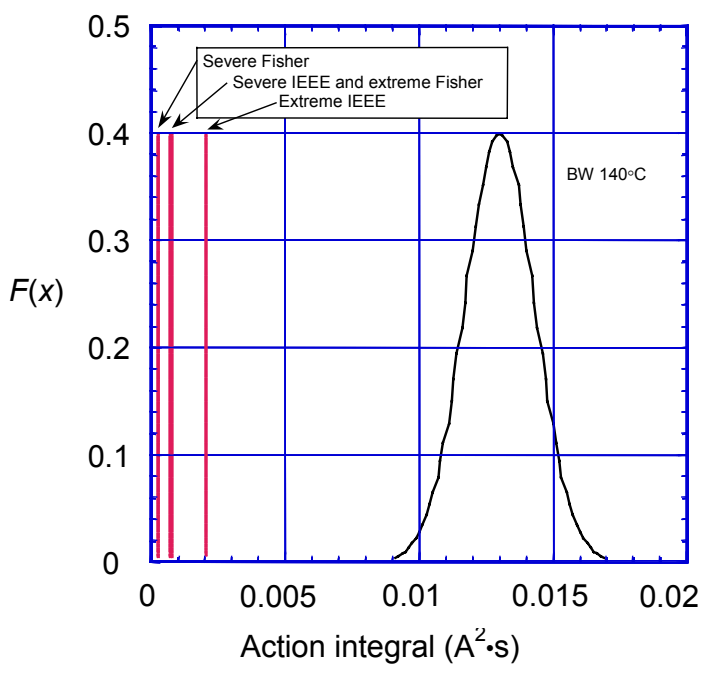

Figure 7. An extreme PESD does not deliver sufficient action integral to achieve the PETN melting temperature of $140^{\circ} \mathrm{C}$ from the EBW.

Table 2 indicates that the extreme PESD level is nominally $12 \%$ of the action integral needed to increase the temperature of the EBW to $140^{\circ} \mathrm{C}$ from the ambient temperature of $20^{\circ} \mathrm{C}$. When the extreme PESD level is mapped over the distribution of the calculated response for the initial EBW response, as shown in Figure 7, it becomes obvious that this insult is not an 
issue or concern for the EBW-type detonator used in this case study.

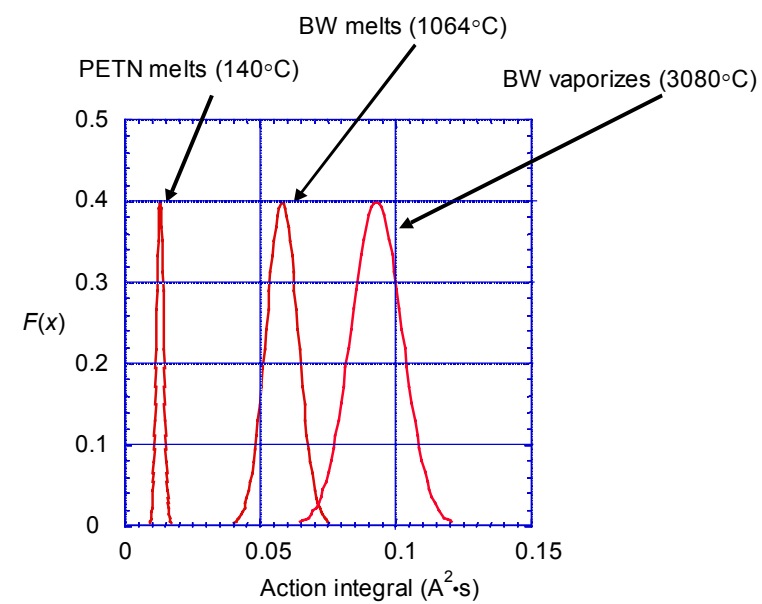

Figure 8. The two remaining response levels of the EBW are the melting and vaporization points.

Extending the calculation to $-7 \sigma$ results in a projection that $<8 \mathrm{E}-12$ of the population would have a threshold level sufficient to cause the EBW to reach a temperature level of $140^{\circ} \mathrm{C}$, the melting temperature of PETN. Experimental results investigating the PESD environment to EBW-type detonators have shown that the high-order response of detonation is not possible. ${ }^{12,13}$ As a result, the fundamental analysis and experimental evidence demonstrate that the extreme PESD environmental insult to this victim is not a concern and therefore screenable.

Furthermore, insult parameters that do not exceed the extreme PESD action integral are subsumed in the victim response to PESD and are likewise screenable.

The approach established to create a population distribution for a specific response of a victim can now be used to assess the remaining areas of concern. By using single-point calculations, similar distributions are generated for both the melting and vaporization phases of the EBW and are shown in Figure 8. The standard deviation for each characteristic is assumed to be $10 \%$, and the mean levels are assumed to be the values listed in Table 4 .
The obvious increase in the associated thresholds for the different low-level effects is illustrated in Figure 8. The projected responses also indicate an overlap of the population between the EBW melting and vaporization phases. A projection of the remaining unintentional electrical environments to the three low-level responses continues with the FESD threat. 


\section{The Furniture or Tooling Electrostatic} Environment

The IEEE standard 62.47 for the FESD environment, as schematically represented in Figure 2, also represents the furniture electrostatic environment and for this discussion is considered to be extreme when $40 \mathrm{kV}$ is used as the source potential. One can then repeat the calculations to model the insult to the victim and project a reasonable response from the population of EBW-type detonators. The significant difference between the PESD and FESD is the lower current-limiting resistance for the FESDequivalent circuit. The lower resistance value shows a definite increase in action integral even though the primary stored energy is the same. Table 5 shows the comparison values used to represent the conservative extreme electrostatic environments. Additional differences in the insult provided by the two ESD environments are shown in Figures 9 and 10. Figure 9 shows the computational current profile of an extreme FESD environment imposed on a $10-\mathrm{m} \Omega$ victim, and Figure 10 shows the calculated action integral.

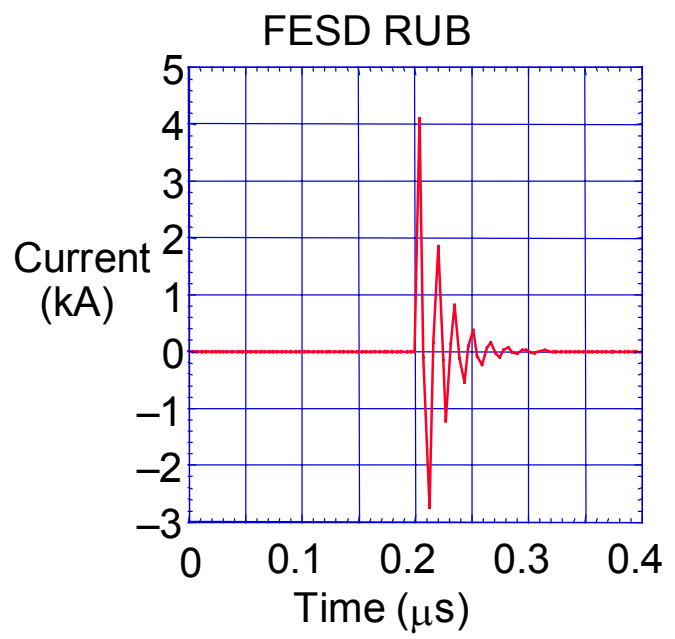

Figure 9. The computational current profile of an extreme FESD insult imposed on a $10-\mathrm{m} \Omega$ EBW indicates an underdamped insult.
Table 5. A range of parameters that is used to define the electrostatic environments (the values used for each extreme electrostatic environment are indicated in parentheses).

\begin{tabular}{|l|l|l|}
\hline $\begin{array}{l}\text { Component or } \\
\text { parameter }\end{array}$ & \multicolumn{1}{|c|}{$\begin{array}{c}\text { IEEE 62.47 } \\
\text { PESD }\end{array}$} & $\begin{array}{c}\text { IEEE 62.47 } \\
\text { FESD }\end{array}$ \\
\hline $\begin{array}{l}\text { Body capacitance } \\
\left(C_{\mathrm{b}}\right)\end{array}$ & $\begin{array}{l}60 \text { to } 300 \mathrm{pF} \\
(300 \mathrm{pF})\end{array}$ & $\begin{array}{l}60 \text { to } 300 \mathrm{pF} \\
(300 \mathrm{pF})\end{array}$ \\
\hline $\begin{array}{l}\text { Body inductance } \\
\left(L_{\mathrm{b}}\right)\end{array}$ & $\begin{array}{l}0.5 \mathrm{to} 2 \mu \mathrm{H} \\
(0.5 \mu \mathrm{H})\end{array}$ & $\begin{array}{l}0.02 \text { to } 0.1 \mu \mathrm{H} \\
(0.02 \mu \mathrm{H})\end{array}$ \\
\hline $\begin{array}{l}\text { Body resistance } \\
\left(R_{\mathrm{b}}\right)\end{array}$ & $\begin{array}{l}150 \text { to } 1500 \Omega \\
(150 \Omega)\end{array}$ & $\begin{array}{l}2 \text { to } 90 \Omega \\
(2 \Omega)\end{array}$ \\
\hline $\begin{array}{l}\text { Hand capacitance } \\
\left(C_{\mathrm{h}}\right)\end{array}$ & $\begin{array}{l}3 \text { to } 10 \mathrm{pF} \\
(10 \mathrm{pF})\end{array}$ & $\begin{array}{l}3 \text { to } 20 \mathrm{pF} \\
(20 \mathrm{pF})\end{array}$ \\
\hline $\begin{array}{l}\text { Hand inductance } \\
\left(L_{\mathrm{h}}\right)\end{array}$ & $\begin{array}{l}0.05 \mathrm{to} 0.2 \mu \mathrm{H} \\
(0.05 \mu \mathrm{H})\end{array}$ & $\begin{array}{l}<0.01 \mu \mathrm{H} \\
(0.01 \mu \mathrm{H})\end{array}$ \\
\hline $\begin{array}{l}\text { Hand resistance } \\
\left(R_{\mathrm{h}}\right)\end{array}$ & $\begin{array}{l}20 \text { to } 200 \Omega \\
(20 \Omega)\end{array}$ & $\begin{array}{l}<20 \Omega \\
(20 \Omega)\end{array}$ \\
\hline $\begin{array}{l}\text { Extreme action } \\
\text { integral }(40 \mathrm{kV}) \\
(240 \mathrm{~mJ})\end{array}$ & $1.6 \mathrm{E}-03 \mathrm{~A}^{2} \cdot \mathrm{s}$ & \multicolumn{1}{c|}{$0.120 \mathrm{~A}^{2} \cdot \mathrm{s}$} \\
\hline
\end{tabular}

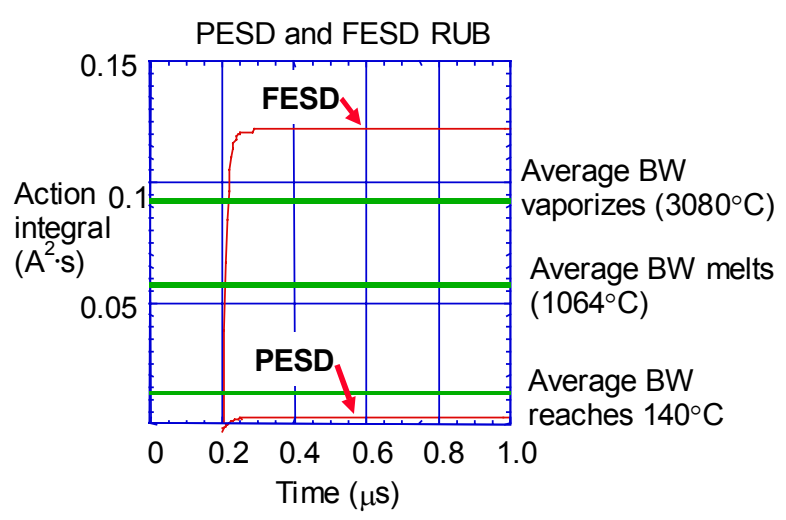

Figure 10. Unlike the PESD, the corresponding action integral of the extreme FESD has been calculated to levels that indicate a possible level of concern for the same victim.

A comparison of the computational FESD to the PESD model as it relates to the reduced series-limiting components in the two environments is illustrated by the results of the circuit analysis shown in Figures 9 and 4 . The initial FESD peak current of $4000 \mathrm{~A}$ is 20 times the PESD/RUB current 
indicated in Figure 4. In addition, the ringing signature, or higher $Q$, of the FESD environment provides a slightly different insult to the victim. The higher $Q$ is directly related to the damping factor of the LRC networks. The associated action integral with the extreme FESD insult is sufficiently large to be of concern and, unlike the PESD environment, cannot be screened out.

Projecting the possible response of the EBW candidate to this level of insult is accomplished by simply mapping the FESDcalculated action integral onto the population response profiles given earlier in Figure 8 and redisplayed in Figure 11.

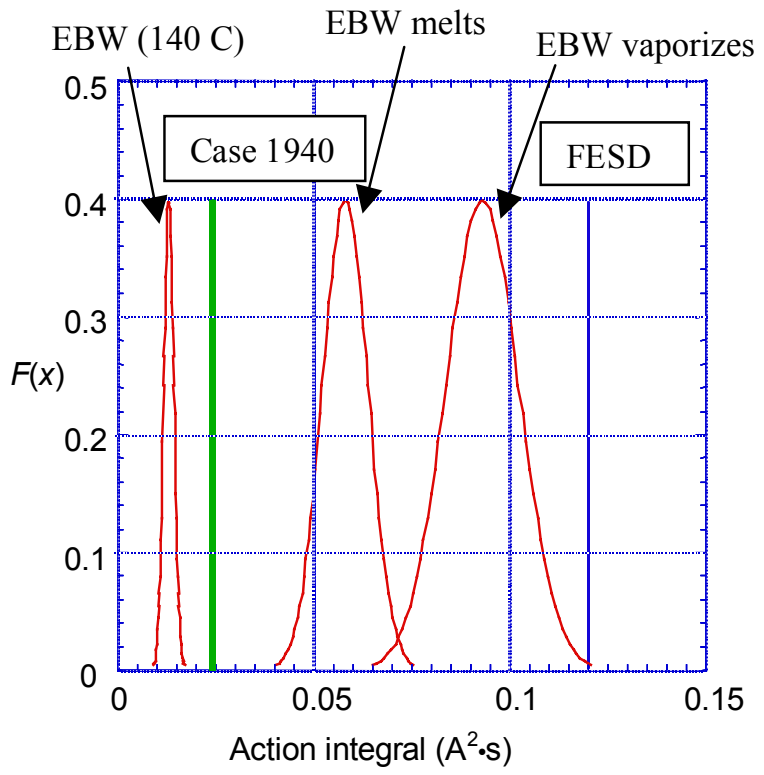

Figure 11. When a reasonable EBW is used as the victim, low-level responses are possible.

Although not all FESD environments are extreme, a low-level response cannot be screened out, as in the case of all PESD environments. When a FESD or TESD environment is adequately defined, a reduced action integral may indicate that a small segment of the population will be affected by the insult. Included in Table 6 is an example of the maximum FESD environment posed in a case study by a representative working group, referred to as case 1940. This controlled environment was given a capacitance and voltage parameter that provided only $12 \%$ of the extreme FESD environment. As a result, the environment provided a reduced insult to the victim. This type of EBW will achieve a temperature of $140^{\circ} \mathrm{C}$ if exposed to this level of insult. In addition, only a portion of the EBW population is expected to melt, and an even smaller number is expected to vaporize. The population distribution calculation was extended to $-7 \sigma$ and resulted in projected estimates for the three responses of interest. These estimates are listed in Table 6.

Table 6. Two examples of FESD-type insults are used to indicate the EBW population response.

\begin{tabular}{|l|l|l|}
\hline $\begin{array}{c}\text { Low-level } \\
\text { response }\end{array}$ & \multicolumn{1}{|c|}{$\begin{array}{c}\text { Extreme } \\
\text { FESD }\end{array}$} & $\begin{array}{c}\text { FESD case } \\
\mathbf{1 9 4 0}\end{array}$ \\
\hline Action integral & $0.120 \mathrm{~A}^{2} \bullet \mathrm{s}$ & $0.024 \mathrm{~A}^{2} \cdot \mathrm{s}$ \\
\hline EBW $\left(140^{\circ} \mathrm{C}\right)$ & 1 & 1 \\
\hline EBW melts & 1 & $<3.27 \mathrm{E}-8$ \\
\hline EBW vaporizes & $<9.96 \mathrm{E}-1$ & $<8 \mathrm{E}-12$ \\
\hline
\end{tabular}




\section{Combined ESD Environments}

A combined PESD and FESD environment should not be generalized in a simplistic manner as being a mere extension of the PESD threat. An excellent view given in IEEE 62.47 and shown in Figure 12 clearly illustrates a credible configuration typically found in universal settings.

The critical issue regarding the combined ESD environment is the amount of energy that can be stored in a lowimpedance source that makes the initial contact to the victim. In the example illustrated in Figure 12, the cart and the person have the same potential, and the cart will provide the initial discharge. The equivalent circuit representing this configuration is shown in Figure 13. The resulting current and action integral are calculated and are shown in Figures 14 and 15 respectively.

The previously mentioned ESD sources, when discrete or combined, have been adequately defined to project the insult onto the low-level response distribution of a typical EBW. The response is an unmitigated response to the insult from the defined ESD environment, given a pin-to-

\section{IEEE 62.47}

CONDUCTIVE HUMAN-TOCART CONTACT

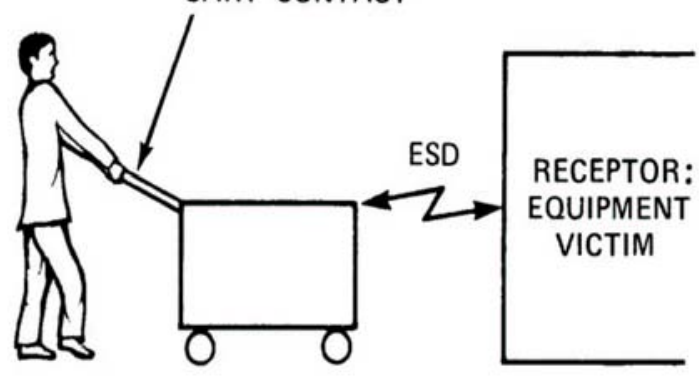

Figure 12. A simple illustration of a combined PESD and FESD environment from the IEEE 62.47 reference.

pin attachment. The complication of determining the response can be reduced by noticing a simple relationship: the action integral is bound by the energy of the source divided by the series resistance of the source. Figure 16 shows how this relationship can be easily applied to a combined environment.

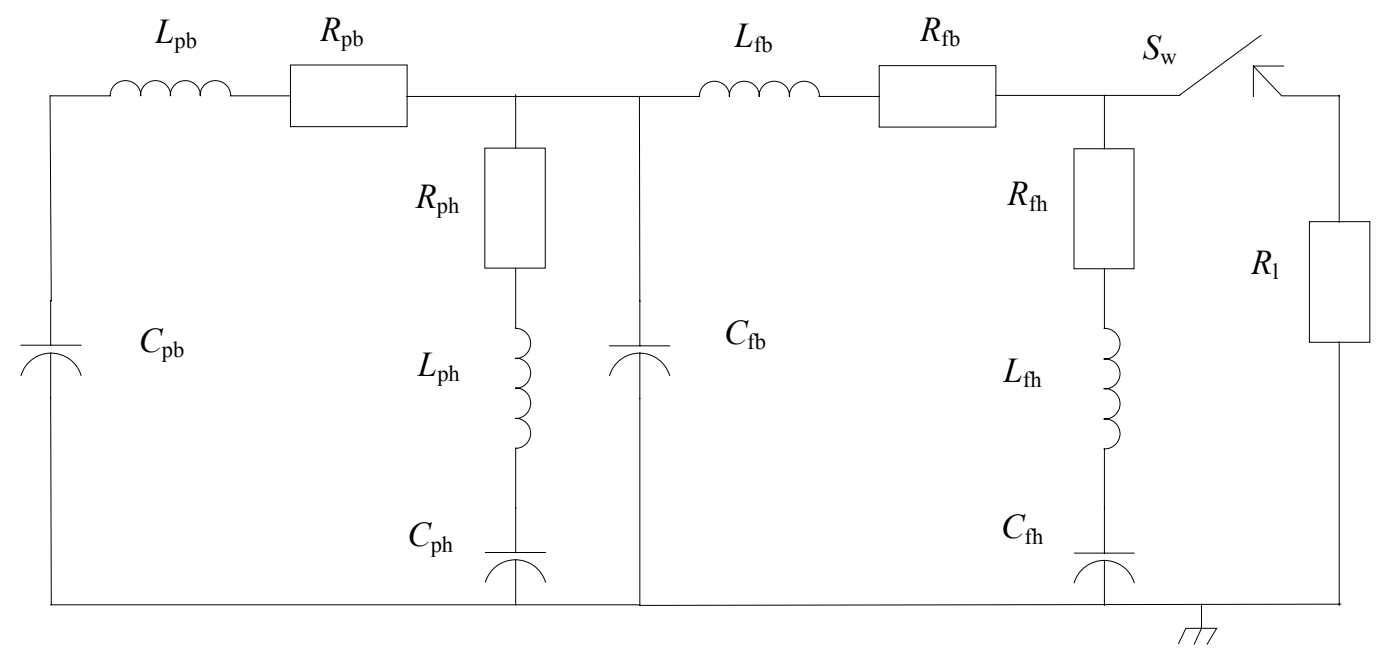

Figure 13. The electrical-equivalent circuit for a combined extreme PESD and FESD environment from the IEEE 62.47 reference. 
UCRL-ID-145642

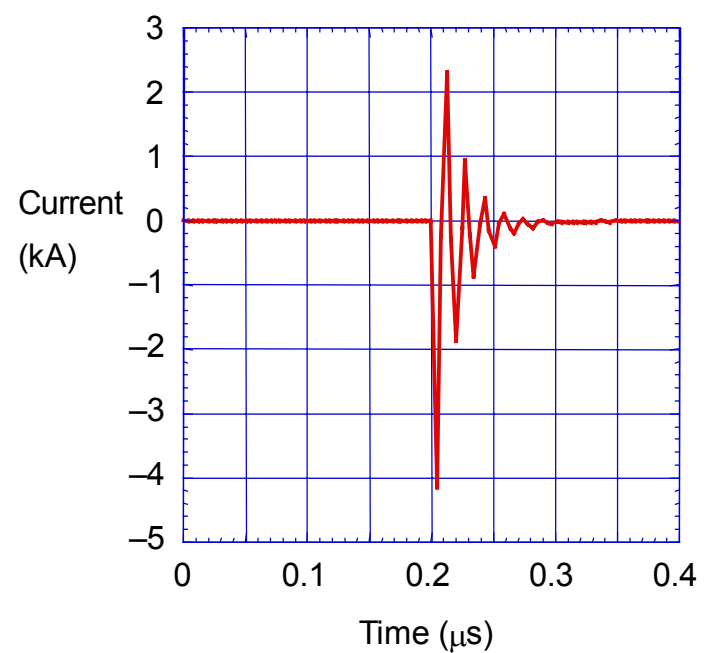

Figure 14. A slight increase in the peak current of a combined extreme ESD environment is shown.

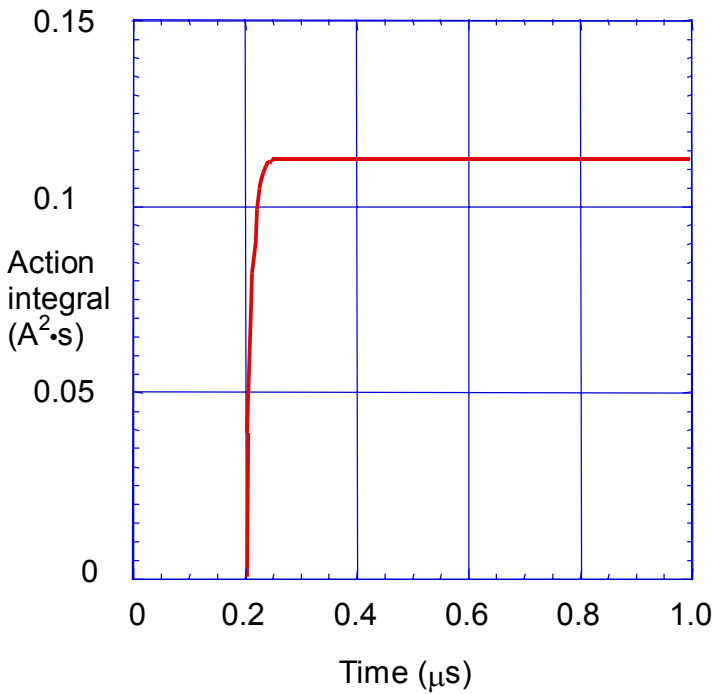

Figure 15. Corresponding to the increase in peak current, a $10 \%$ increase in action integral is calculated for the combined ESD threat.

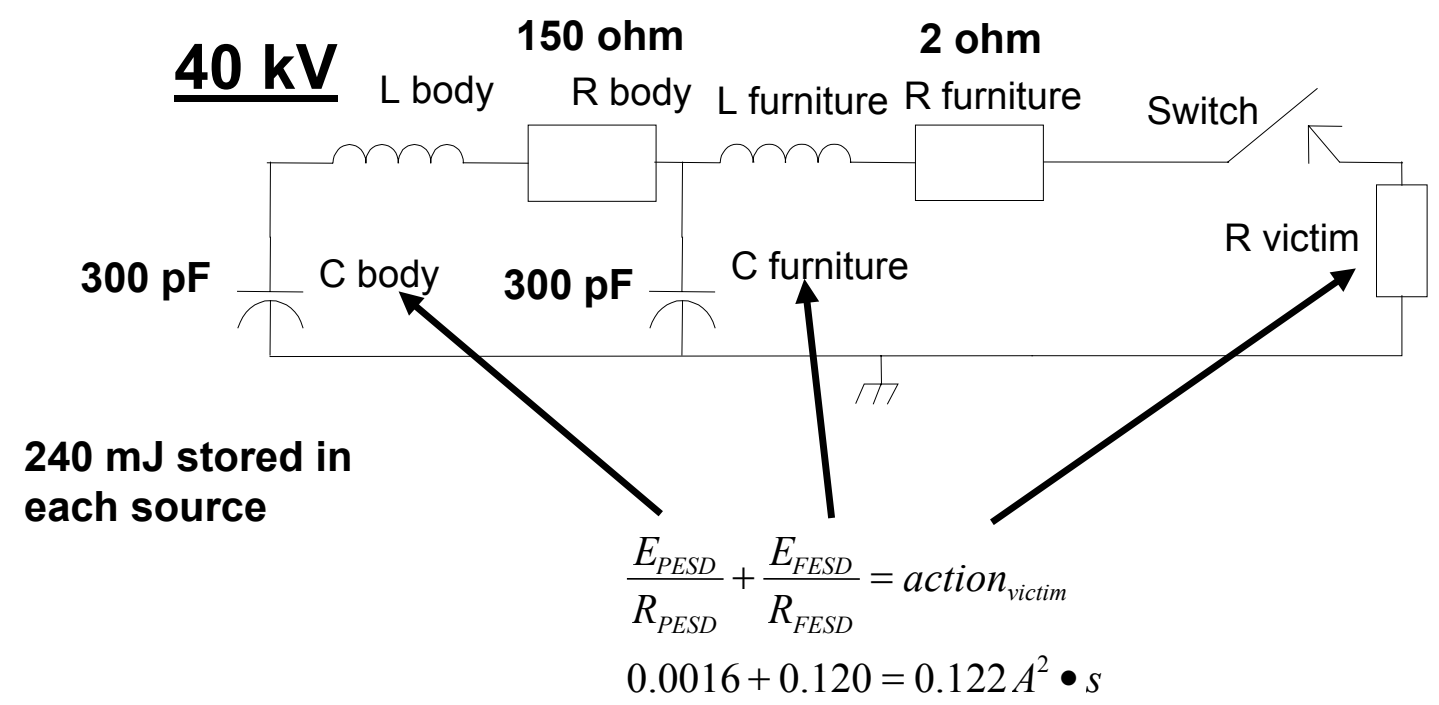

Figure 16. The above schematic represents the relationship of a combined electrostatic environment created by a person and a piece of furniture.

The computational model of the ESD threat provides insight into the interaction between the source and the victim. However, a simplified approach to determine the action integral can be used to easily assess areas of concern. Typically, objects such as workstations have controlled geometries. These geometries can be used to define equivalent capacitors. If the accepted severe voltage level of $25 \mathrm{kV}$ is used as the source voltage, then the source energy is easily calculated. The ratio of the source energy to the source series resistance then indicates the insult parameter of concern, the action integral. The insult has also been shown to include, when applicable, the human and tooling/furniture environments as a combined environment. If an environmental insult causes a low-level of concern, then additional parameters are used to further assess the possible response (Table 3).

If the response is considered acceptable or insignificant, then no mitigation is required. If, however, a reduction in the 
response is desired, then proper mitigation is required. There are two basic mitigation options: engineered and administrative. This discussion continues later with limited engineered controls that are recommended for a typical detonator.

\section{Pin-to-Case Response}

There are two credible paths for putting current or action integral through the EBW of the detonator. The obvious path is through the detonator cable as designed, or "pin-to-pin." The second, less obvious path occurs from a sufficient insult scenario attached to a conductor of the detonator cable and returned to the source through ground, referred to as "pin-to-case."

Figure 17 illustrates a representative schematic of a source, detonator cable, EBW, and the capacitance coupling each of these components together. The normal operation of the detonator is to inject current from source point $\mathrm{A}$ and return the current to source point $B$. When points $A$ and $B$ are shorted, they are electrically tied to the same potential, and no significant current will

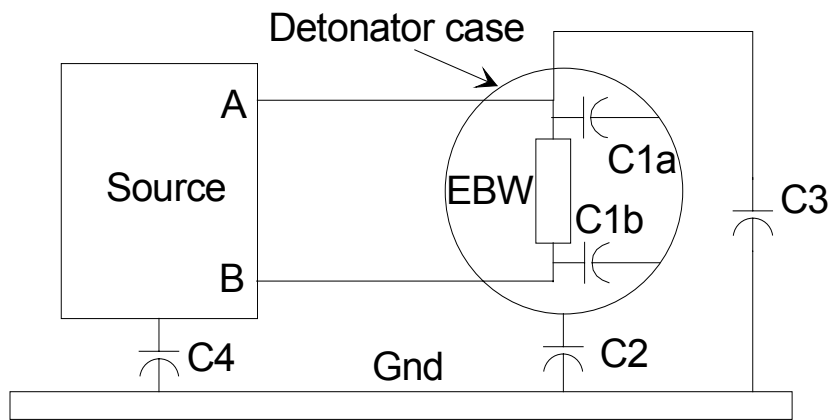

Figure 17. A schematic representation of the relationship of the source and detonator showing the capacitive coupling. flow through the EBW. If, however, a transit type of insult occurs at point B or, in our case study, the shield of the detonator cable, a capacitive-coupled insult couples through the detonator. This does not become a concern until the voltage across the related capacitive components exceeds the voltage breakdown level across the dielectric material defining the capacitor. At this point, the capacitor shorts allowing the insult to pass through the victim. The equivalent model used to solve for the value of the insult is given in Figure 18. 


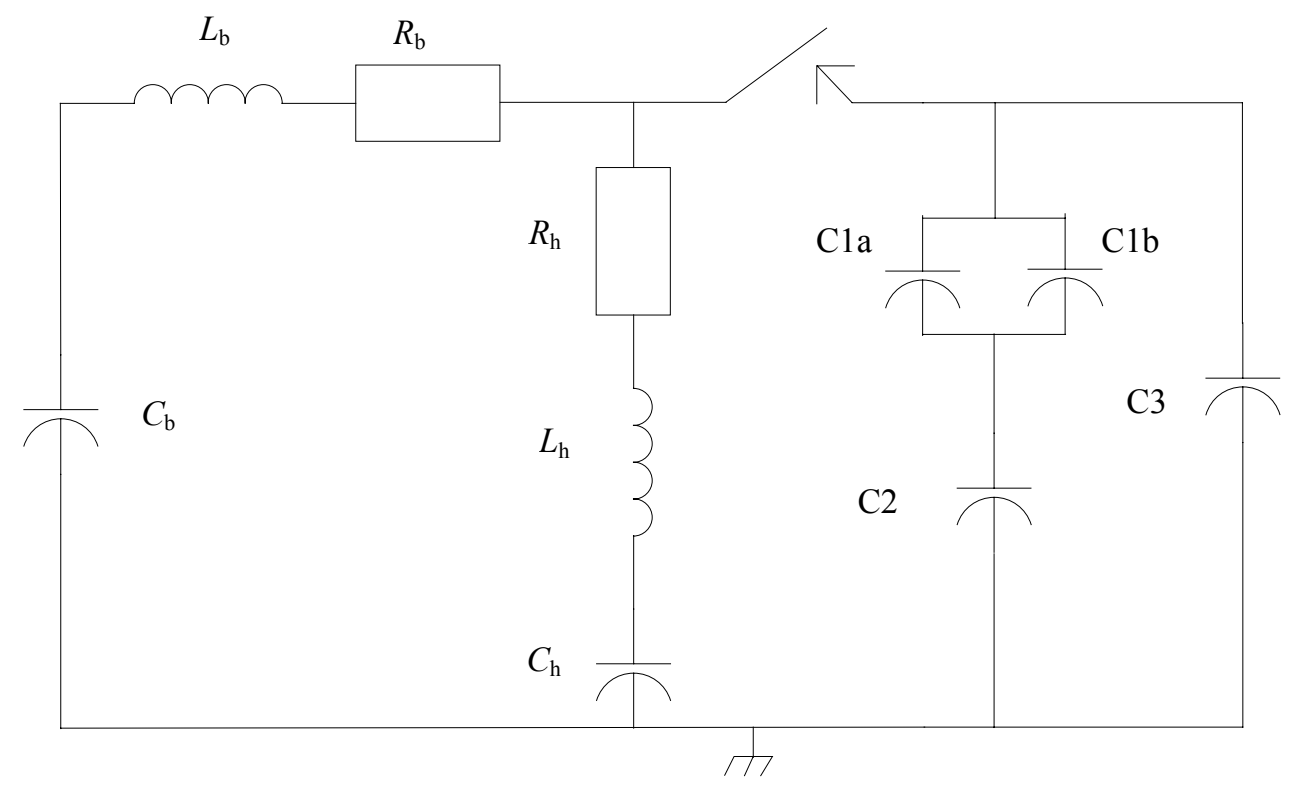

Figure 18. An electrical-equivalent circuit for the extreme FESD environment provides the solution for the insult.

The analysis of the equivalent circuit shows that the amount of charge transferred from the source to the victim indicates only a slight change in the ESD environment level. The values for the indicated capacitances as calculated by a 3-D finiteelement analysis (FEA) application are

$$
\begin{array}{ll}
\text { C1 a \& C1b } & 0.0937 \mathrm{pF} \\
\text { C2 } & 1.2364 \mathrm{pF} \\
\text { C3 } & 0.0146 \mathrm{pF}
\end{array}
$$

The source, as indicated in Figure 17, is capacitively coupled to ground. In most ESD environments, the source will have the same return path, or ground, as the victim. If the source is sufficiently isolated from ground, then the insult currents are reduced. The difficulty is controlling and maintaining these open circuits.

\section{Pin-to-Case Calculations}

The circuit simulation results of an extreme ESD insult into a capacitive load, as indicated in Figure 18, simply charges up the related capacitors $(\mathrm{C} 1, \mathrm{C} 2$, and $\mathrm{C} 3)$ to the ESD or source level. It is easily shown that an air dielectric medium in the detonator would not be able to sustain this voltage level. To investigate a reasonable maximum level of voltage breakdown in this geometry, a 3-D finite-element analysis (FEA) application by Ansoft is used to calculate the field stress. Figures 19 and 20 show the evaluation specimen that represents a sample EBW insulated from a backing plate and a close-up of the detonator, respectively. 


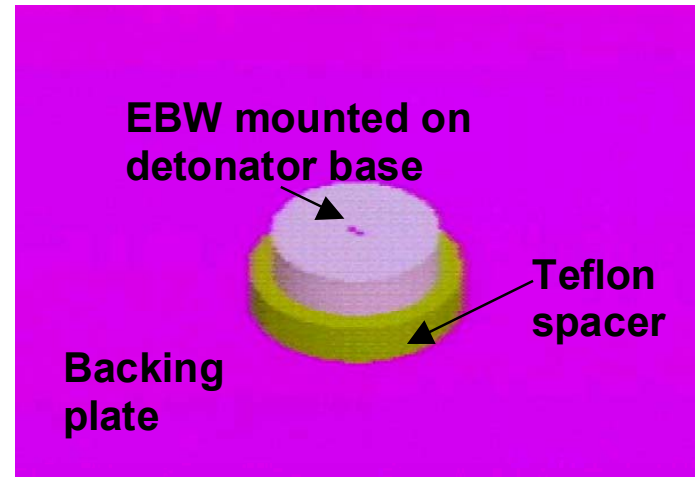

Figure 19. The detonator examined in this discussion consists of an EBW mounted on a dielectric member that is separated from a backing plate by a Teflon spacer.

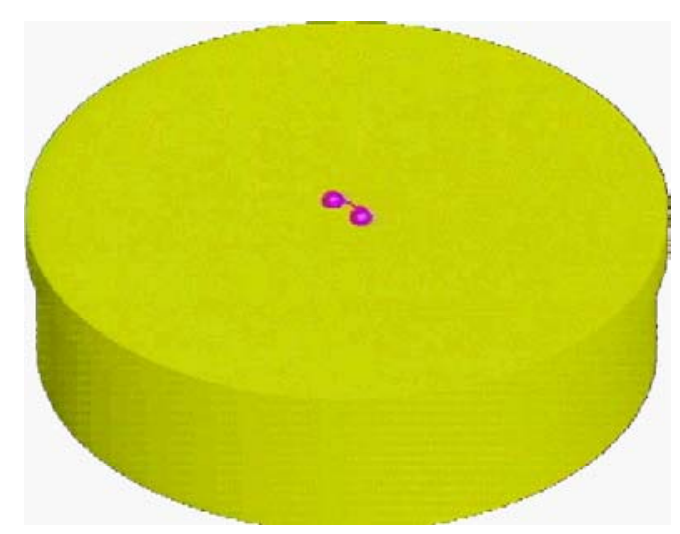

Figure 20. A close-up view of the EBW shows the small 0.0015 -in. gold wire bridging the two detonator attachment points.

Different runs of the same geometry have resulted in slightly different solutions. These differences are typically within 1 to $2 \%$. This lack of convergence can be attributed to the method used by the application to set up the tetrahedrons that define the geometry. As a result, in one run, as shown in Figure 21, the maximum field stress was found to be on the top surface of the EBW near the center of the bridge between the two solder points. However, because of the EBW's symmetrical geometry, the maximum field stress should be at the absolute center. The difference is

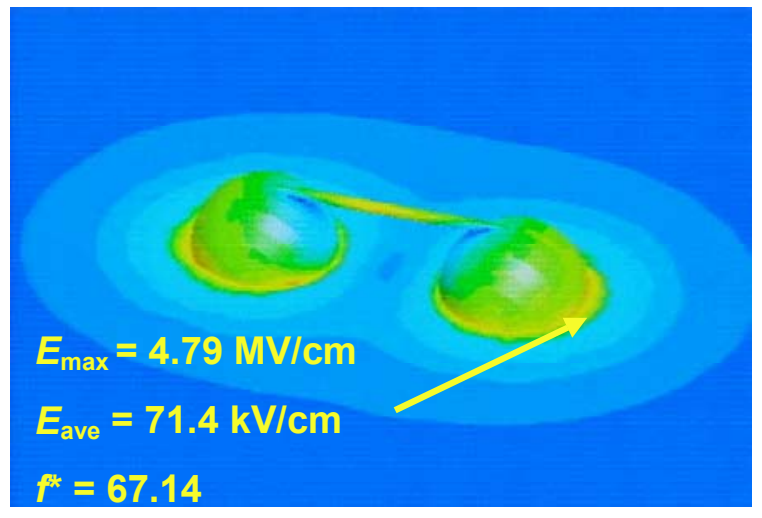

Figure 21. A 45-deg close-up view of the field stress calculation shows the locational dependency for the maximum field stress $\left(E_{\max }\right)$.

basically $<1 \%$ and is considered insignificant. Rotating the view $45 \mathrm{deg}$ shows another set of equally valid solutions, which are used for the continued discussion.

Figure 21 shows the calculated highest field stress $\left(E_{\max }=4.79 \mathrm{MV} / \mathrm{cm}\right)$ at the triple junction defined by the base of the attachment point of the BW, the surrounding $\mathrm{HE}$ dielectric material, and the dielectric substrate of the detonator. The average field stress $\left(E_{\text {ave }}\right)$ for this point is found by simply dividing the applied voltage, $40 \mathrm{kV}$, by the distance to the case $(71.4 \mathrm{kV} / \mathrm{cm})$. The resulting field enhancement $\left(f^{*}\right)$ of 67.1 for this specific geometry is then given by the ratio of maximum field stress $\left(E_{\max }\right)$ divided by the average field stress $\left(E_{\text {ave }}\right)$, as shown in Eq. 6. The maximum air field stress $(30 \mathrm{kV} / \mathrm{cm})$ divided by $f^{*}$ then yields the average field stress $\left(E_{\text {ave }}\right)$ of the pin-to-case required to cause failure or air breakdown (Eq. 7). The voltage difference from the pinto-case needed to cause breakdown ( $V_{\text {breakdown }}$ ) is found by multiplying $E_{\text {ave }}$ by the distance $(d)$, as shown in Eq. 8. The maximum voltage ( $\left.V_{\text {breakdown }}\right)$ before the air between the pin and case breaks down is then calculated to be $257 \mathrm{~V}$. 


$$
\begin{aligned}
& f^{*}=\frac{E_{\max }}{E_{\text {ave }}}=67.14 \\
& E_{\text {ave }}=\frac{E_{\max }}{67.14}=\frac{30 \mathrm{kV} / \mathrm{cm}}{67.14}=447 \mathrm{~V} / \mathrm{cm} \\
& V_{\text {breakdown }}=E_{\text {ave }} \times d=257 \mathrm{~V}
\end{aligned}
$$

Field stress calculations have shown that the pin-to-case capacitance $(\mathrm{Cla}$ and $\mathrm{C} 1 \mathrm{~b}$, as shown in Figure 18) will short or fail at calculated level of $257 \mathrm{~V}$. Actual DC breakdown levels were measured on this specific geometry, and the observed voltage was $4.7 \mathrm{kV}$. This significant difference demanded a review of the calculations. The review concluded that the calculations appear to be accurate. Work is continuing to resolve the confusion caused by the results, but the current hypothesis is that the field enhancement is so high that the EBW has a corona-stabilized geometry. Corona stabilization occurs when a highly enhanced electrode emits an electron cloud that conceptually increases the electrode size.

An alternate measurement to DC

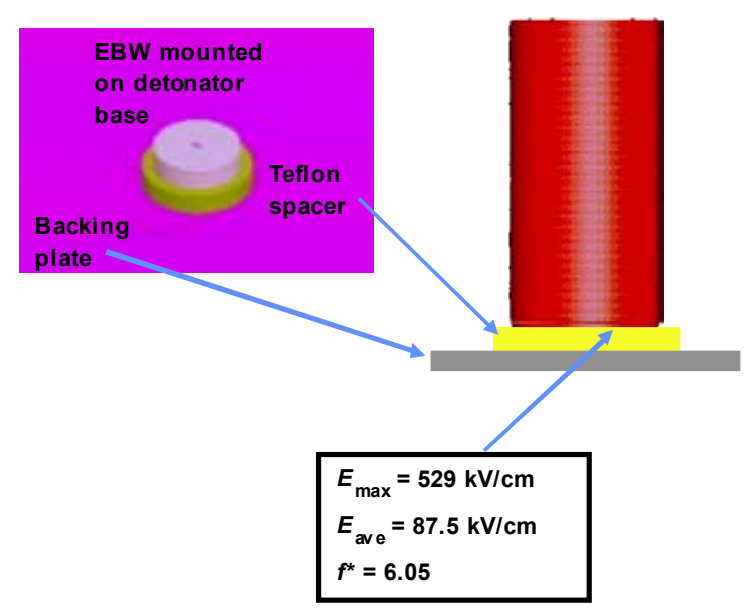

Figure 22. When the case of the detonator is crimped around the base, the maximum field stress is calculated to be on the intersurface of the case.

$$
\begin{aligned}
& f^{*}=\frac{E_{\max }}{E_{\text {ave }}}=6.0498 \\
& E_{\text {ave }}=\frac{E_{\max }}{6.05}=\frac{30 \mathrm{kV} / \mathrm{cm}}{6.05}=4.958 \frac{\mathrm{kV}}{\mathrm{cm}} \\
& V_{\text {breakdown }}=E_{\text {ave }} \times d=2.267 \mathrm{kV}
\end{aligned}
$$

breakdown used a partial discharge analysis approach, which corroborated the highly stressed structure by indicating the onset of corona activity to be streamer-type in nature instead of the typical Townsend-type. ${ }^{14}$ When reported in the literature, this phenomenon usually involves electronegative gases or close-proximity dielectric material. Lower field-enhanced geometries are better understood and characterized using this approach. Nonetheless, when an insult to the victim exceeds the determined $V_{\text {breakdown, }}$ the voltage at the case equals the pin voltage and, as such, must have sufficient electrical insulation or strength from the base or else it, too, will subsequently fail. In this discussion, either the $25-$ or $40-\mathrm{kV}$ insult is sufficient to break down the pin-to-case capacitance.

A conductive casing is used to hold the explosive clamps to the detonator base and mounts on an insulated washer $4.6 \mathrm{~mm}$ ( 0.180 in.) above a backing plate. The electrical-equivalent component for this segment is shown as C2 in Figure 18. The results of the FEA field calculations are shown in Figure 22. The highest field stress was observed at the intersurface edge of the case and detonator base.

The calculated $E_{\max }$ and $E_{\text {ave }}$ at this location are 529 and $87.5 \mathrm{kV} / \mathrm{cm}$ respectively. The associated field enhancement (Eq. 9) is 6.05. Using the air as the surrounding dielectric medium and ignoring the conceptual overlapping edge of the insulating washer, which may not be in a typical configuration, the breakdown voltage is calculated to be $2.27 \mathrm{kV}$, as shown in Eq. 10 and 11. Again, the high field 
enhancement of the detonator case-to-plate indicates that measurements are needed to better indicate the level of concern.

A summary view of an insult of sufficient voltage to cause pin-to-case and case-to-plate voltage breakdown is illustrated in Figure 23. The calculations and measurements indicate that voltages greater than $4.7 \mathrm{kV}$ are adequate to fault the detonator from pin-to-case. On the other hand, considering a severely enhanced caseto-plate geometry and a linear breakdown estimate of $2.27 \mathrm{kV}$, the detonator would most likely hold 5 to $10 \mathrm{kV}$ and fail at the extreme ESD level of $40 \mathrm{kV}$. Measuring the breakdown voltage of a representative configuration is needed to further gauge the insult at severe ESD levels.

In general, extreme ESD environments appear to exceed the level of insult required to provide an unintentional current path for the environment. Furthermore, if an unintentional attachment is made to an opposing EBW attachment point that does not arc to the case/plate, then the insult will pass through the EBW, just as in the pin-topin attachment scenario. The detonator response expands to include the EBW and arc/HE response.

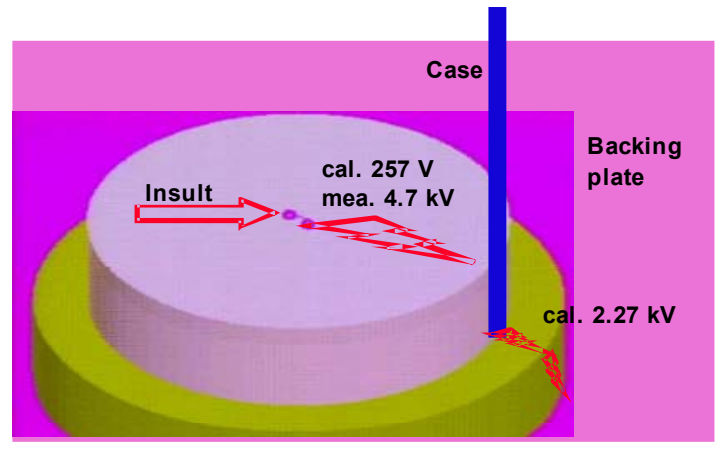

Figure 23. A visual indication of the resulting calculations/measurements (cal./mea.) showing a pin-to-case/plate fault scenario.

Up to this point, the discussion has dealt with the attachment of an ESD environment to the pin or conductor of an EBW.

However, for the sake of completeness, the capacitive coupling of an insult to a conductor must be included as a means to insult the victim. Figure 24 clearly shows how an ESD impulse can couple through the outer insulation of a coaxial detonator cable into the EBW and out of the detonator, as previously described. The outer dielectric

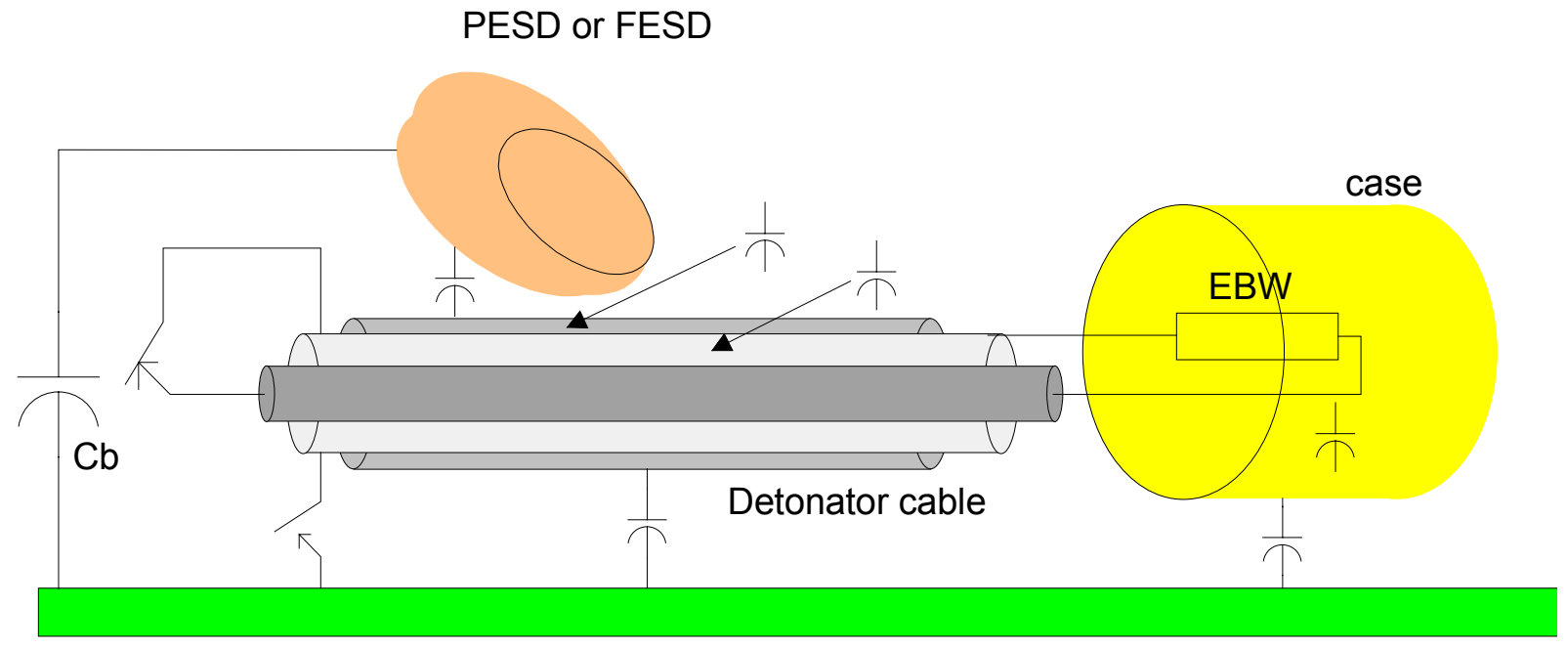

Ground or Backing plate

Figure 24. Detonators are shown to be susceptible to capacitive-coupled environments. 
insulation does not have to initially fail in this configuration to effectively couple the entire insult to the victim. As each capacitor fails to an overvoltage level, the increase in voltage across the remaining capacitors stresses the capacitors to their levels of failure. This problem is exaggerated when the environment is an FESD insult.

\section{Pin-to-Case Experimental Evidence}

Experimental evidence of detonator responses resulting in arc initiated detonation is shown to be arc-energy dependent $^{16}$. The required arc-energy is also shown to have a linear relationship to length for small gaps ( $\sim 30$ mils $)$ with a nominal energy per length value of $1 \mathrm{~mJ} / \mathrm{mil}$. This empirical value applies to high-surface area PETN, and as such cannot be inferred to be the necessary arc-energy required for all spark initiation of detonators. The limited knowledge of the arc characteristics and HE interaction does not provide sufficient confidence to extrapolate the reported energy per length to large gaps having a spacing of 250 mils. The only credible ESD insults capable of providing the level of initiating arc-energy are low resistance sources having sufficient stored energy. Low resistance environments allow more energy to be dissipated across the arc and less across the source. As such high resistance sources are seen to reduce the insult level available for arc initiation by allowing most of the energy to be dissipated in the source and less in the arc.

Work by others experimentally confirm the inability of high resistance ESD environments such as HESD to meet the insult threshold for detonation. ${ }^{12,13}$ Authors ${ }^{13}$ considered the HESD insult as the worst case environment and calculated a lower resistance source, similar to the discussed TESD and FESD type, as a possible environment for detonation. The experimental configuration ${ }^{13}$ consisted of a $450 \mathrm{~mJ}$ source. Of the detonators tested only small gap (40 mil) units with low-density powder detonated. The larger 250 mil gaps with a combined low and high density pressing, $0.93 \mathrm{~g} / \mathrm{cm}^{3}$ and $1.60 \mathrm{~g} / \mathrm{cm}^{3}$ respectively, did not detonate.

Assuming an optimum coupling circuit for a source and arc, it must be pointed out that only one half of the stored energy from the source will be developed across an arc. As such a reasonable amount of arc energy from the defined experimental configuration would be $225 \mathrm{~mJ}$. This energy level is only slightly less than the $250 \mathrm{~mJ}$ if extrapolated from the $1 \mathrm{~mJ} / \mathrm{mil}$ level for small gaps. In addition this discussion shows that TESD and FESD environments are more significant than previously thought. The highest environmental insult in a recently conducted safety study includes a $25 \mathrm{kV}$ source having a capacitance of $13 \mathrm{nF}$ providing $4 \mathrm{~J}$ of stored energy from a low resistance FESD type source. This level of energy insult has not been previously assessed and exceeds the investigated level by an order of magnitude. The resulting detonator response is therefore unknown.

In order to apply the same rigor of assessment to the pin-to-case response as discussed for the pin-to-pin configuration additional information is required defining the arc resistance. Arc resistance in this media is not easily achieved from first principles. An experimental effort has been started to empirically provide this critical parameter needed to comprehensively assess the response of detonators to ESD-type environments.

\section{Insult Mitigation}

Engineered controls are the preferred method of mitigating insults. The following section advocates shorting pin-to-pin and pin-to-case detonator leads.

The initial case of shorting the pin-to-pin removes the field gradient across the BW that is needed to conduct current, so the 
insult is no longer a concern. If the center and outer conductors are shorted and the voltage is adequate to fault the pin-tocase/plate capacitance, then the current will divide according to the impedance of two paths to ground. As discussed above, when the voltage exceeds the breakdown level, the current will pass along the detonator header adjacent to the HE. The detonator response to this type of insult is not well defined and is not recommended. In contrast, however, if the center and outer conductors are shorted and the short is electrically connected to the ground by a low impedance, only a minimal voltage will develop across the pin-tocase/plate capacitances. The resulting low voltage will isolate the conducted current from passing through the detonator and will allow the environment to discharge through the shorted connections.

Clearly, the highest level of mitigation is to short the detonator cable and connect it to ground with a low-impedance attachment.

\section{Conclusion}

The fundamental and experimental verified charge transfer by triboelectrification does not adequately bound the ESD environment. A simplified approach to determining the action integral uses a controlled geometry to define the capacitance and the accepted severe level of $25 \mathrm{kV}$ to determine the source energy. The ratio of the source energy to the source series resistance then indicates the insult parameter of concern, the action integral. The insult has also been shown to include, when applicable, the human and tooling/furniture environments as a combined environment.

This discussion independently confirms that all PESD environments that are appropriately defined solely as a PESD environment can be screened as an insult causing a low-level effect to include both pin-to-pin and pin-to-case configurations. In contrast, the extreme FESD environment indicates that low-level responses are anticipated and need to be evaluated on a case by case bases.

Pin-to-pin configurations are evaluated from first principles whereas arc initiation by pin-to-case scenarios is not as well defined and therefore limited to an empirical interpretation for assessment. The confidence in scaling the available information for arc initiation from small gaps to large gaps is not reasonable considering the lack of the understanding in the arc formation and its associated critical parameters for detonation. A recent safety study indicates an environmental insult having an order of magnitude higher energy than previously investigated. Ongoing work is underway to measure the arc resistance with the intent to improve the estimate of available energy distribution in larger gap configurations.

\section{Acknowledgements}

I would like to thank Wes Davis for the single-point calculations of the evaluation EBW, David Mayhall for the 3-D field calculations, Donald Harrison for his assistance in converting the field calculations to pictures, and Zoher Chiba and Jeff Hagerty for their editorial comments.

\section{References}

1. W. D. Greason, Electrostatic Damage in Electronics: Devices and Systems, (Research Studies Press Ltd., Letchworth Hertfordshire, England, 1987), pp. 46-47.

2. W. D. Greason, "Investigation of a Test Methodology for Triboelectrification," EOS/ESD Symposium, 344-351 (1999).

3. CRC Handbook of Chemistry and Physics, $71^{\text {st }}$ ed. (CRC Press, Inc., 1990), pp. 1286.

4. L. L. Alston, High-Voltage Technology (Spottiswoode, Ballantyne, and Co. Ltd., London, 1968), pp. 47-48. 
5. R. J. Fisher, A Severe Human Model for Safety and High Reliability System Qualification Testing, Sandia National Laboratories, SAND-89-0194C (1989).

6. IEEE STD 62.47 1992, IEEE Guide on Electrostatic Discharge (ESD)

Characterization of the ESD Environment, March 16, 1993.

7. R. J. Fisher, The Electrostatic Discharge Threat Environment Database and Recommended Baseline Stockpile-toTarget Sequence Specification, Sandia National Laboratories, SAN88-2658 UC-13 (1988).

8. P. W. Cooper, Technology of Explosives (Wiley-VCH, New York, 1996).

9. P. W. Cooper, Explosives Engineering (Wiley-VCH, New York, 1996), pp. 42, 360-366.

10. H. P. Westman, Ed., Reference Data for Radio Engineers, $4^{\text {th }}$ ed. (International Telephone and Telegraph Corporation, New York, 1956), pp. 988-989.

11. R. E. Walpole and R. H. Myers, Probability and Statistics for Engineers and Scientists, $5^{\text {th }}$ ed. (Prentice Hall, Englewood Cliffs, NJ, 1993), pp. 141156.

12. T. J. Tucker, Spark Initiation Requirements of a Secondary Explosive, Sandia National Laboratories, SC-R-681759, (1968).

13. R. S. Lee and R. E. Lee, Electrostatic Discharge Effects on EBW Detonators, Lawrence Livermore National Laboratory, UCRL-ID-105644, (1991).

14. R. Bartnikas, Engineering Dielectrics Vol. I: Corona Measurement and Interpretation [(American Society for Testing and Materials (ASTM), 1979)], pp. 27-31.

15. Aircraft Lightning Protection Handbook, U. S. Department of Transportation, Federal Aviation Administration, DOT/FAA/CT-89/22, September 1989, pp 120-121.

16. T. J. Tucker, J. E. Kennedy, and D. L.

Allensworth, Secondary Explosive Spark
Detonators, Sandia National Laboratories, SC-R-713486, (1971). 